\title{
Evolution of Total Polyphenols Content and Antioxidant Activity in Broccoli Florets during Storage at Different Temperatures
}

\author{
Andrea Mahn and M. Paz Rubio \\ Departamento de Ingeniería Química, Universidad de Santiago de Chile, Avenida Libertador Bernardo O’Higgins 3363, \\ Estación Central, 9170019 Santiago, Chile
}

Correspondence should be addressed to Andrea Mahn; andrea.mahn@usach.cl

Received 19 June 2017; Revised 18 August 2017; Accepted 27 August 2017; Published 3 October 2017

Academic Editor: Senem Kamiloglu

Copyright (C) 2017 Andrea Mahn and M. Paz Rubio. This is an open access article distributed under the Creative Commons Attribution License, which permits unrestricted use, distribution, and reproduction in any medium, provided the original work is properly cited.

\begin{abstract}
Broccoli has great potential as functional food because of its high content of bioactive compounds. Polyphenols are to a great extent responsible for the high antioxidant activity of broccoli. An important challenge to keep the health promoting properties of broccoli is preservation, with freezing and refrigeration being the preferred methods. Despite storage at low temperature reduces the rate of deterioration reactions, some reactions still occur, thus affecting the content of bioactive compounds. In this work, we investigated the evolution of total polyphenols content and antioxidant activity in blanched and unprocessed broccoli florets during storage at different temperatures $\left(-45^{\circ} \mathrm{C}\right.$ to $\left.20^{\circ} \mathrm{C}\right)$. Both antioxidant activity and total polyphenols content increased at the beginning of storage at $-21,-1,10$, and $20^{\circ} \mathrm{C}$, followed by a decrease. Storage at $-45^{\circ} \mathrm{C}$ produced no significant variations. The uneven behavior of antioxidant activity precluded modeling. The evolution of polyphenols was well described by a two-consecutive-reaction model, with $r \geq 0.86$ and MSE $\leq 0.1$. The Ea values obtained for polyphenols formation $(27-32 \mathrm{~kJ} / \mathrm{mol})$ and degradation $(26-38 \mathrm{~kJ} / \mathrm{mol})$ confirm that, in both unprocessed and blanched broccoli, the same reactions are responsible for the evolution of polyphenols content. Our results may contribute to design preservation strategies of broccoli.
\end{abstract}

\section{Introduction}

Broccoli (Brassica oleracea var. italica) is recognized as a "super-food" because of the numerous healthy effects exerted by its high content of bioactive compounds such as glucosinolates, sulforaphanes, polyphenols, ascorbic acid, and minerals [1]. Altogether, these compounds confer high antioxidant activity to this vegetable. Glucosinolates and sulforaphane are recognized as anti-cancer compounds [2]; ascorbic acid acts as cellular antioxidant and protects from cardiovascular diseases [3]; and minerals such as selenium contribute to maintain the homeostasis [4]. Given the high antioxidant activity of polyphenols, the intake of these compounds reduces the risk to developing degenerative diseases triggered by oxidative stress [5]. They also have the capability to prevent diabetes, ulcer, osteoporosis, and cancer $[6,7]$.
Broccoli is a climacteric and highly perishable vegetable; therefore its preservation through processing is essential. However, domestic or technological processing affects to a different extent the healthy properties of broccoli, by altering the content and bioavailability of the bioactive compounds. Freezing and refrigeration are the most common preservation methods used for vegetables. Although low temperature reduces significantly the rate of deterioration reactions, some changes still occur during storage in these conditions. In addition, preprocessing such as cutting and blanching affects the content of bioactive compounds in broccoli [8].

There are some studies about the evolution of polyphenols' content and antioxidant activity in Brassicaceae during storage. Volden et al. [9] reported that the total polyphenols' content in cauliflower significantly decreased after blanching and slightly decreased after storage at $-24^{\circ} \mathrm{C}$ for one year. 
The loss of antioxidant activity was much more marked. Patras et al. [10] reported that the antioxidant activity of broccoli subjected to blanching and freezing was significantly lower in comparison with unprocessed broccoli. Blanching and freezing did not affect significantly the polyphenols content. Finally, Amodio et al. [11] proposed a kinetic model to describe the evolution of polyphenols content in freshcut vegetables during storage. The model considers an initial increase of polyphenols due to the activation of phenylalanine ammonia-lyase (PAL) triggered by abiotic stress, followed by a decrease due to the action of polyphenol oxidase (PPO). The model was validated with experimental data obtained at 0 and $5^{\circ} \mathrm{C}$.

The aim of this work was to investigate the evolution of total polyphenols content and antioxidant activity in blanched and unprocessed broccoli florets during storage at temperatures ranging from $-45^{\circ} \mathrm{C}$ to $20^{\circ} \mathrm{C}$.

\section{Material and Methods}

2.1. Plant Material. Broccoli (Brassica oleracea var. italica) heads were purchased at the local market (Santiago, Chile) to a single supplier. Broccoli heads were processed immediately after purchasing as follows: after washing, they were cut into single florets of $5 \mathrm{~cm}$ length and $0.7-0.9 \mathrm{~cm}$ width (stem) and blanched at $57^{\circ} \mathrm{C}$ for $13 \mathrm{~min}$ [12]. The blanching conditions were chosen in order to keep the antioxidant activity of the fresh vegetable. After that, broccoli florets were put in an icewater bath for $5 \mathrm{~min}$, then put in sealed plastic bags, and stored at different temperatures as stipulated by the experimental design. The unprocessed broccoli heads followed the same process without blanching.

2.2. Experimental Design. Blanched and unprocessed broccoli florets were stored at different temperatures: $20^{\circ} \mathrm{C}$ (controlled ambient temperature), $10^{\circ} \mathrm{C}$ (refrigerator), $-1^{\circ} \mathrm{C},-21^{\circ} \mathrm{C}$ (household freezers), and $-45^{\circ} \mathrm{C}$ (industrial freezer), for up to 83 days, depending on the preservation status of the vegetable. Temperature was checked with a k-type thermocouple. Broccoli florets were kept in plastic sealed bags, with each one containing approximately 50 -g of the vegetable. In each condition, 39 bags with blanched broccoli and 39 bags with unprocessed broccoli were used. In this way, in each sampling procedure three blanched and three unprocessed broccoli bags were taken for analyses. For storage at $20^{\circ} \mathrm{C}$, samples were taken after $0,1,2,6,7$, and 9 days of storage. For storage at 10 and $-1^{\circ} \mathrm{C}$, sampling was conducted every two days until day 15 , and every three days until day 41 , when the vegetable was decomposed. For storage at -21 and $-45^{\circ} \mathrm{C}$, samples were taken every 5 days until day 15 and once a week until day 83 .

2.3. Antioxidants Extraction. The extraction of antioxidant compounds was performed as reported by Vinson et al. [13]. A 200-mg aliquot of liquid nitrogen-pulverized broccoli heads was accurately weighed in a vial, and $4 \mathrm{~mL}$ of $80: 20$ (mL: $\mathrm{mL}$ ) methanol: water solution was added. The mixture was ultrasound processed through a titanium probe immersed in the vial for three minutes at $80 \%$ duty cycle, as reported by Montes-Bayón et al. [14]. Then the samples were incubated at room temperature in an orbital shaker for $4 \mathrm{~h}$. After that, samples were centrifuged at $12000 \times \mathrm{g}$ for $5 \mathrm{~min}$ to remove the solids. The supernatant was recovered, and $80: 20$ $(\mathrm{mL}: \mathrm{mL})$ methanol/water solution was added to complete $5 \mathrm{~mL}$ extract volume.

2.4. Total Polyphenols' Content. The total polyphenols' content (TPP) was determined spectrophotometrically through the Folin-Ciocalteu method [15]. $180 \mu \mathrm{L}$ extract and $90 \mu \mathrm{L}$ Folin-Ciocalteau reagent (diluted 1:1) were added to $360 \mu \mathrm{L}$ distilled water. The mixture was homogenized and left in the dark for $5 \mathrm{~min}$. Then, $450 \mu \mathrm{L}$ of a $200 \mathrm{~g} \mathrm{~L}^{-1}$ sodium carbonate solution was added and left in darkness for $30 \mathrm{~min}$. After that, samples were centrifuged at $12000 \times \mathrm{g}$ for $5 \mathrm{~min}$ to remove the precipitate, and absorbance at $750 \mathrm{~nm}$ was measured. The results were expressed as mg of gallic acid equivalents per 100 gram of dry matter (mg GAE $\left.(100 \mathrm{~g})^{-1} \mathrm{DM}\right)$. The measurements were made in triplicate, and average values were reported.

\subsection{Antioxidant Activity}

2.5.1. Free Radical Scavenging Ability. The free radical scavenging ability (FRSA) of the broccoli extracts was measured using the stable radical 2,2-diphenyl-1-picrylhydrazyl $\left(\mathrm{DPPH}^{\circ}\right.$ ) [16]. 40- $\mu \mathrm{L}$ vegetable extract (at 6 dilutions) were mixed with $1.960 \mu \mathrm{L}$ DPPH solution $\left(6 \times 10^{-5} \mathrm{M}\right.$ in methanol). The absorbance decrease at $515 \mathrm{~nm}$ was continuously recorded during 30 minutes. The $\mathrm{DPPH}^{\bullet}$ concentration in the reaction mixture at zero time and after 30 minutes was calculated by means of a calibration curve, and the remaining $\mathrm{DPPH}^{\bullet}$ concentration was obtained [17]. The measurements were made in triplicate, and the average values were reported.

2.5.2. Hydrogen Peroxide Scavenging Activity. The hydrogen peroxide scavenging activity (HPSA) was assessed through the method reported by Oktay et al. [18]. The methanol extracts were concentrated in a rotatory evaporator (Stuart RE-300, United Kingdom, Great Britain) to dryness and then resuspended into the initial volume with HPLC-grade water. $100 \mu \mathrm{L}$ of aqueous antioxidants extract was added to $900 \mu \mathrm{L}$ of a $4 \mathrm{mM} \mathrm{H}_{2} \mathrm{O}_{2}$ solution in phosphate buffer ( $\mathrm{pH} 7.4$ ). Two control mixtures were used: one contained HPLC-grade water instead of extract and the other contained phosphate buffer instead of $\mathrm{H}_{2} \mathrm{O}_{2}$ solution. Absorbance was measured at $230 \mathrm{~nm}$. HSPA was expressed as percentage with respect to control. The measurements were made in triplicate, and the average values were reported.

2.6. Kinetic Model. The evolution of TPP content was described by the mechanism proposed by Amodio et al. [11], given in (1), considering that polyphenols synthesis is mediated by PAL and their degradation is mediated by PPO. In (1), $P_{\text {pre }}$ is polyphenols precursor, $P$ is polyphenols, $O$ is oxidized compounds, and $k_{1}$ and $k_{2}$ are the rate constants.

$$
P_{\text {pre }} \stackrel{k_{1}}{\longrightarrow} P \stackrel{k_{2}}{\longrightarrow} O .
$$


The kinetic model is given by (2), where $C_{\text {pre }}, C_{P}$ and $C_{O}$ are the concentrations of polyphenols precursors, polyphenols, and oxidized compounds, respectively.

$$
\begin{aligned}
-\frac{d C_{\text {pre }}}{d t} & =k_{1} \cdot C_{\text {pre }}, \\
\frac{d C_{P}}{d t} & =k_{1} \cdot C_{\text {pre }}-k_{2} \cdot C_{P}, \\
\frac{d C_{O}}{d t} & =k_{2} \cdot C_{P} .
\end{aligned}
$$

The analytical solution of the system composed by (2) is given by (3), where $C_{\text {pre, } 0}$ is the initial concentration of the precursor, and $C_{P}$ and $C_{P 0}$ are the TPP content at $t=t$ and $t=0$, respectively. The model was solved by estimating $k_{1}, k_{2}$ and $C_{\text {pre, } 0}$ from the experimental data. The dependence of the rate constants from temperature was considered to follow the Arrhenius equation.

$$
\frac{C_{P}}{C_{P 0}}=e^{-k_{2} t}+\frac{C_{\text {pre }, 0}}{C_{P 0}} \frac{k_{1}}{k_{2}-k_{1}}\left(e^{-k_{1} t}-e^{-k_{2} t}\right) .
$$

2.7. Statistical Analyses. Two-sample comparison was performed through Student's $t$ test at 95\% confidence using the software Statgraphics ${ }^{\text {TM }}$ Centurion XVII (Statistical Graphics Corp., USA, 2013). Model adjustment to the experimental data resulted from minimization of the sum of squares, and the fit quality was assessed by the Pearson's correlation coefficient and mean squared error ( $r$ and MSE, resp.), using Microsoft Excel 2013.

\section{Results and Discussion}

3.1. Evolution of the Antioxidant Activity. The antioxidant activity, measured as free radical scavenging ability (FRSA) and as hydrogen peroxide scavenging activity (HPSA), was determined at different intervals during storage, in blanched and unprocessed broccoli florets. Figures 1 and 2 show FRSA and HPSA of broccoli florets during storage at $20^{\circ} \mathrm{C}$ (a), $10^{\circ} \mathrm{C}$ (b), $-1^{\circ} \mathrm{C}(\mathrm{c}),-21^{\circ} \mathrm{C}(\mathrm{d})$, and $-45^{\circ} \mathrm{C}(\mathrm{e})$, respectively. Blanching significantly reduced the FRSA of broccoli florets ( $p$-value $=0.0045)$, agreeing with the literature $[9,19]$, probably due to the thermal decomposition of antioxidants such as ascorbic acid. A similar behavior was obtained for HPSA; however the differences were not statistically significant. During storage at $20^{\circ} \mathrm{C}$ and $10^{\circ} \mathrm{C}$, the FRSA of unprocessed broccoli increased until 2 days of storage; after that it showed a progressive decrease. This behavior agrees with the evolution of TPP content. Then, the initial increase of FRSA may obey an increase in the activity of PAL leading to a higher TPP content that was reflected in the antioxidant activity. The decrease of FRSA observed after 2 days of storage may be attributed to a decrease in TPP content due to the action of PPO. Besides, the extractability of the antioxidant compounds was probably affected by the structural changes induced by blanching. HPSA showed no statistically significant differences along the storage period at 10 and $20^{\circ} \mathrm{C}$. The FRSA of unprocessed florets was significantly higher than FRSA of blanched florets until 6 days of storage, after that there were no statistically significant differences in FRSA between blanched and unprocessed broccoli.

In storage at $-1^{\circ} \mathrm{C},-21^{\circ} \mathrm{C}$ and $-45^{\circ} \mathrm{C}$, FRSA of unprocessed broccoli increased in time with respect to the initial condition $(t=0)$, and in most cases the difference was statistically significant. On the contrary, FRSA of blanched broccoli was similar to the initial FRSA and showed no clear trend in time. FRSA of blanched and unprocessed broccoli showed a decreasing trend until the 9th day of storage at $-1,-21$, and $-45^{\circ} \mathrm{C}$, agreeing with Patras et al. [10], who studied the effect of low temperature preservation of blanched broccoli during 7 days. From the 9th day onwards there was no clear trend, observing increase and decrease of FRSA at different times. This contradicts with the results of Volden et al. [9], who reported that the antioxidant activity of blanched broccoli stored at $-24^{\circ} \mathrm{C}$ decreased in time. This difference may be explained by the different span of the storage periods used in both studies; the authors measured the antioxidant properties at $0,3,6$, and 12 months of storage, while in the present study the storage period was much shorter $(83$ days). In addition, the authors quantified the antioxidant activity through ORAC and FRAP, while in the present study we measured the FRSA using DPPH stable free radical. In general, FRSA of unprocessed broccoli was higher than that of blanched broccoli during storage at freezing temperature, and it increased in time. This behavior may be attributed to tissue damage produced by the formation of ice crystals during frozen storage. Additionally, enzyme activity is higher in unprocessed broccoli resulting in a higher TPP content that was reflected in the antioxidant activity.

The HPSA of blanched broccoli was in most cases higher than that of unprocessed broccoli during storage at $-1,-21$, and $-45^{\circ} \mathrm{C}$, opposing the results obtained for FRSA. The HPSA of both unprocessed and blanched broccoli showed a slight increase at the beginning of storage at $-1,-21$ and $-45^{\circ} \mathrm{C}$, followed by a decrease. This agrees with the observations of FRSA at the same temperatures.

In summary, the behavior of antioxidant activity during storage at different temperatures is affected by several factors simultaneously, which are difficult to isolate one from the others. Besides, the antioxidant activity depends on many compounds whose concentration and chemical properties differ considerably. This hinders the development of a kinetic model to describe the evolution of FRSA of broccoli during storage.

3.2. Evolution of the TPP Content. The total polyphenols content (TPP) was determined at different time intervals during the storage periods, in blanched and unprocessed broccoli florets. Figure 3 shows the TPP content of broccoli florets during storage at $20^{\circ} \mathrm{C}$ (Figure $\left.3(\mathrm{a})\right), 10^{\circ} \mathrm{C}$ (Figure $\left.3(\mathrm{~b})\right),-1^{\circ} \mathrm{C}$ (Figure 3(c)),$-21^{\circ} \mathrm{C}$ (Figure 3(d)), and $-45^{\circ} \mathrm{C}$ (Figure 3(e)). In all cases, blanching did not affect significantly the TPP content, resulting in similar values at the beginning of storage. This contradicts Faller and Fialho [15] who reported significant losses of phenolic compounds in broccoli after domestic cooking. This contradiction may be related to the mild blanching conditions used in the present study. TPP content 


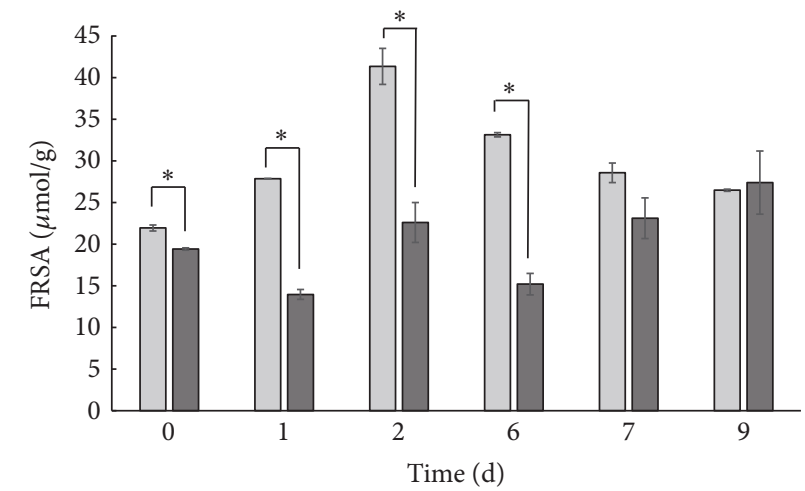

(a)

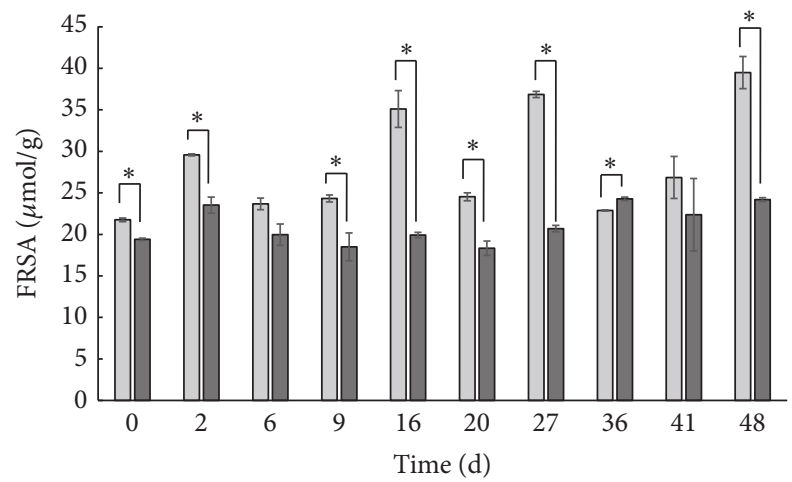

(c)

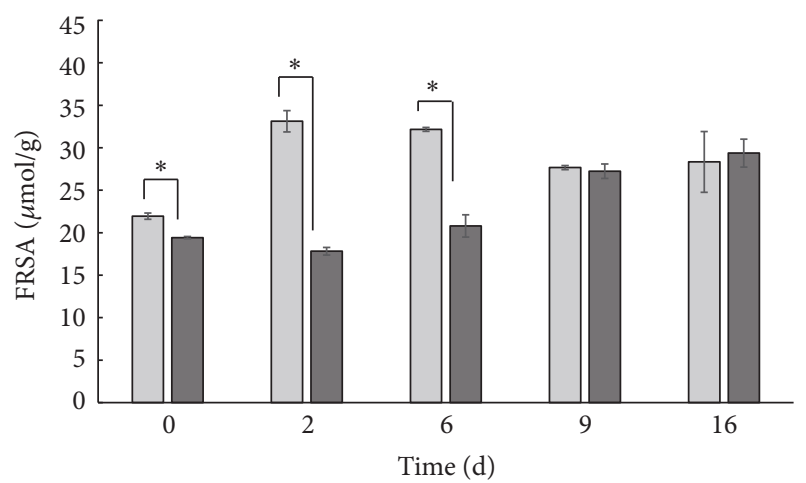

(b)

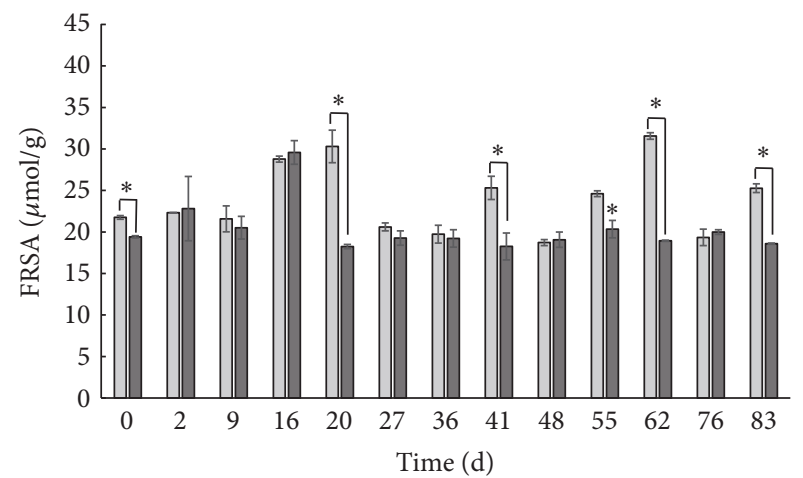

(d)

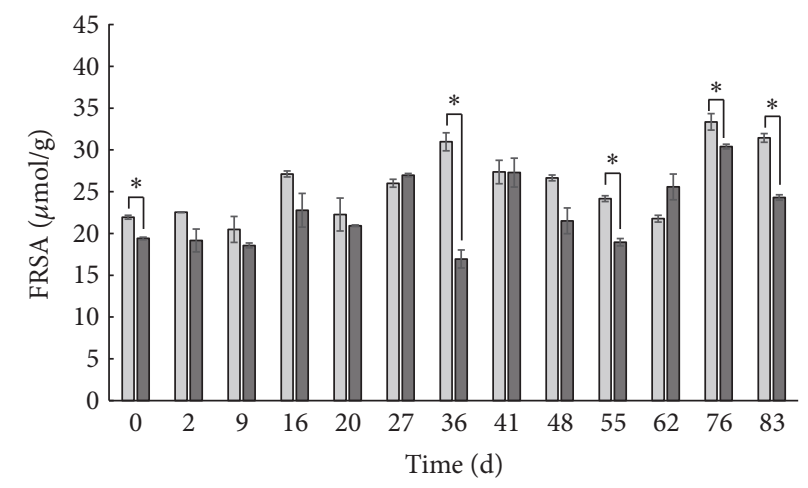

(e)

FIGURE 1: Evolution of the free radical scavenging ability (FRSA) in blanched (dark bars) and unprocessed (light bars) broccoli florets during storage at $20^{\circ} \mathrm{C}(\mathrm{a}), 10^{\circ} \mathrm{C}(\mathrm{b}),-1^{\circ} \mathrm{C}(\mathrm{c}),-21^{\circ} \mathrm{C}(\mathrm{d})$, and $-45^{\circ} \mathrm{C}(\mathrm{e})$. Significant differences $(p<0.05)$ between blanched and unprocessed broccoli are highlighted with “*”.

suffered an initial increase followed by a decrease towards the end of the storage period at all temperatures except at $-45^{\circ} \mathrm{C}$. This behavior agrees with the work of Amodio et al. [11], who proposed a kinetic model to describe the phenolic content of fresh-cut broccoli during storage at $5^{\circ} \mathrm{C}$. The model considers a two-consecutive-reaction mechanism that explains the increase in TPP content form day 0 until day 6 , and after that a decrease until day 12 . The authors attributed this behavior to an initial increase of the activity of the enzyme PAL triggered by abiotic stress, followed by the action of PPO that degrades phenolic compounds. The different behavior observed at $-45^{\circ} \mathrm{C}$ may obey the extremely low reaction rates, preventing the enzymatic degradation of polyphenols.

In storage at $20^{\circ} \mathrm{C}$, the TPP content was higher in unprocessed broccoli than in blanched broccoli, along the complete storage period, with statistically significant differences after 1 and 7 days. During storage at $10^{\circ} \mathrm{C}$ there were no statistically significant differences between TPP of blanched and unprocessed broccoli during the complete period. Both blanched and unprocessed broccoli increased significantly the TTP during storage with respect to the initial condition (at $t=0$ ), except for day 16th where TPP in blanched broccoli was similar to that found at the beginning of the 


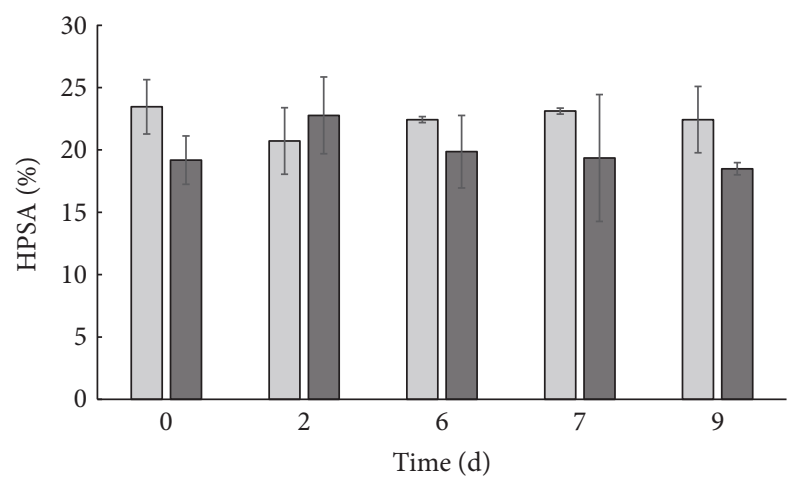

(a)

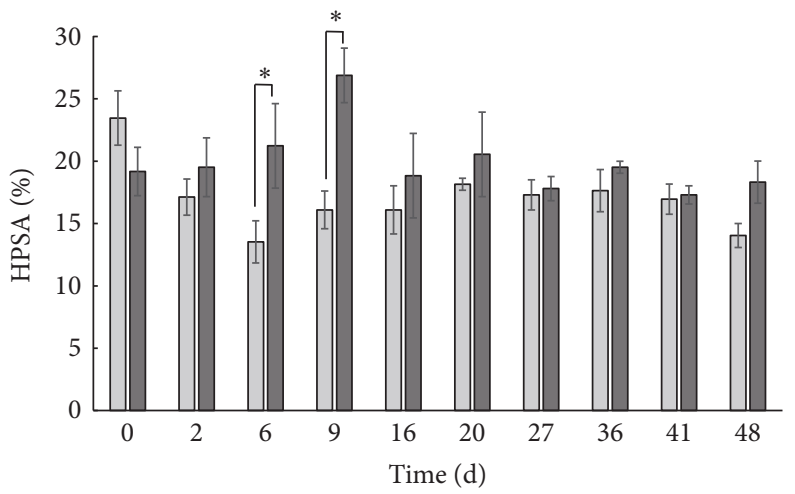

(c)

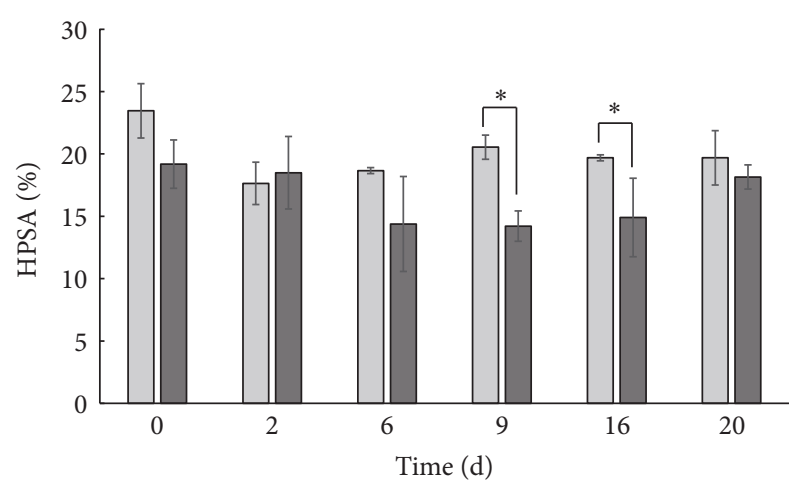

(b)

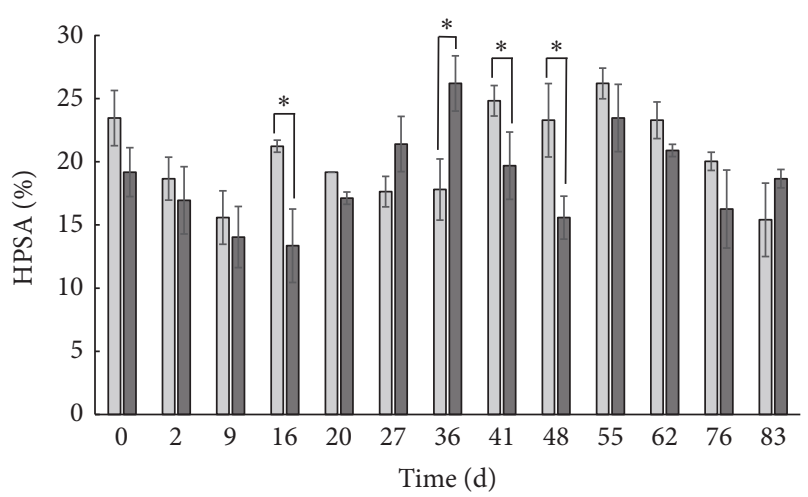

(d)

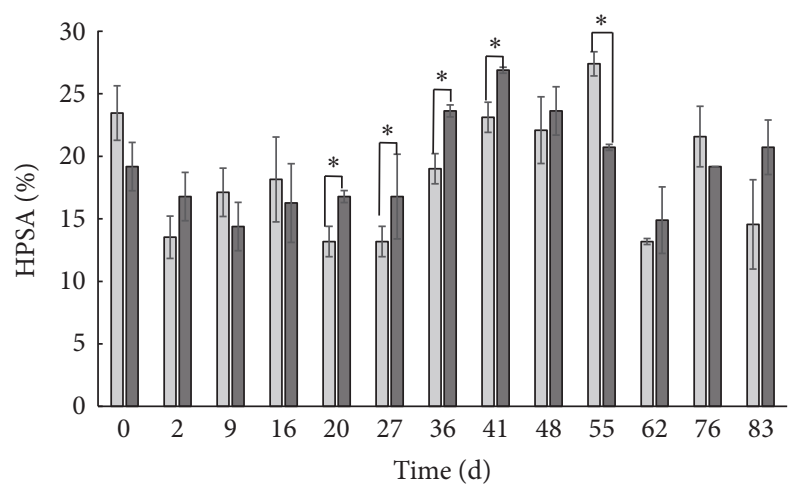

(e)

FIGURE 2: Evolution of the hydrogen peroxide scavenging activity (HPSA) in blanched (dark bars) and unprocessed (light bars) broccoli florets during storage at $20^{\circ} \mathrm{C}(\mathrm{a}), 10^{\circ} \mathrm{C}(\mathrm{b}),-1^{\circ} \mathrm{C}(\mathrm{c}),-21^{\circ} \mathrm{C}(\mathrm{d})$, and $-45^{\circ} \mathrm{C}(\mathrm{e})$. Significant differences $(p<0.05)$ between blanched and unprocessed broccoli are highlighted with “*”.

storage period. The fact that both blanched and unprocessed broccoli florets showed no significant differences in TPP during storage at $10^{\circ} \mathrm{C}$ may be explained by the similar level of tissue damage caused by the action of some endogenous plant or microbial enzymes, which degrade vegetable walls, thus favoring extractability equally for both blanched and unprocessed florets. It has to be noted that the blanching treatment was not intense enough to totally reduce the microbial charge or to completely inactivate all the vegetable enzymes. Hence after blanching there was residual microbial and enzymatic activity.
During storage at $-1^{\circ} \mathrm{C}$, the TPP content in unprocessed broccoli was significantly higher after 9,27 , and 36 days (Figure 3(c)). The data suggest that blanched broccoli had lower TPP content during storage at this temperature. This may be attributed to the better extractability in unprocessed broccoli due to a higher activity of cell wall breaking enzymes. In blanched broccoli, the TPP content was similar to the initial condition ( $p$-value $>0.05$ ) during most of the storage period, except at 2 and 6 days of storage, when TPP was slightly higher than the initial one. This may be attributed to the action of PAL and the cell wall breaking enzymes that 


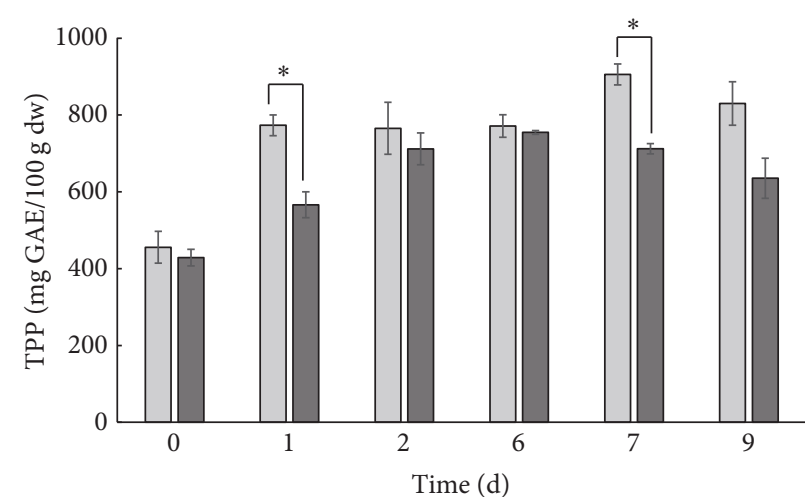

(a)

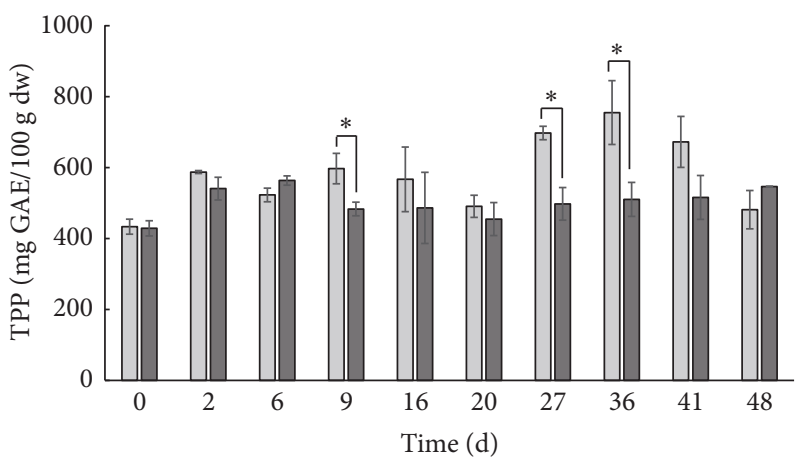

(c)

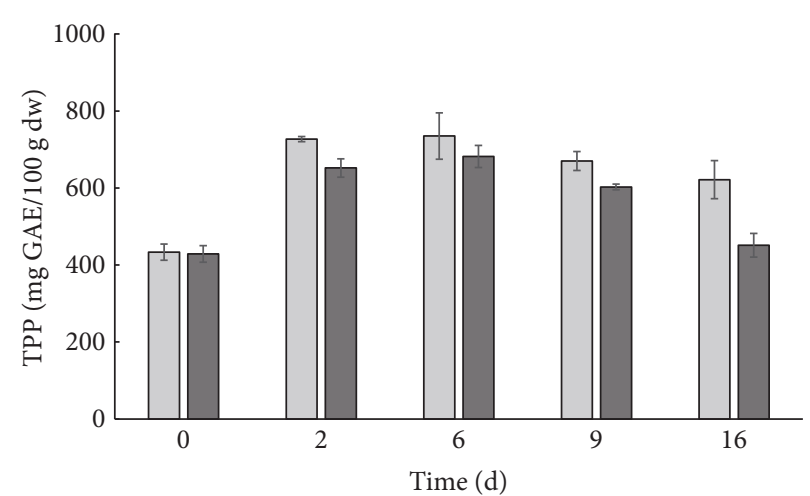

(b)

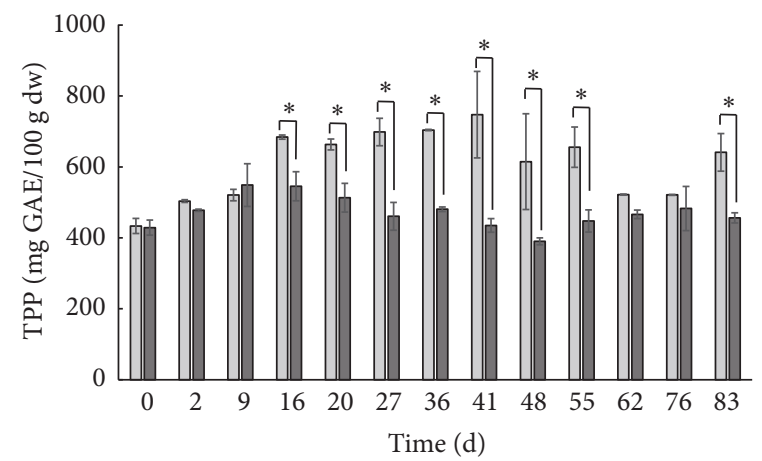

(d)

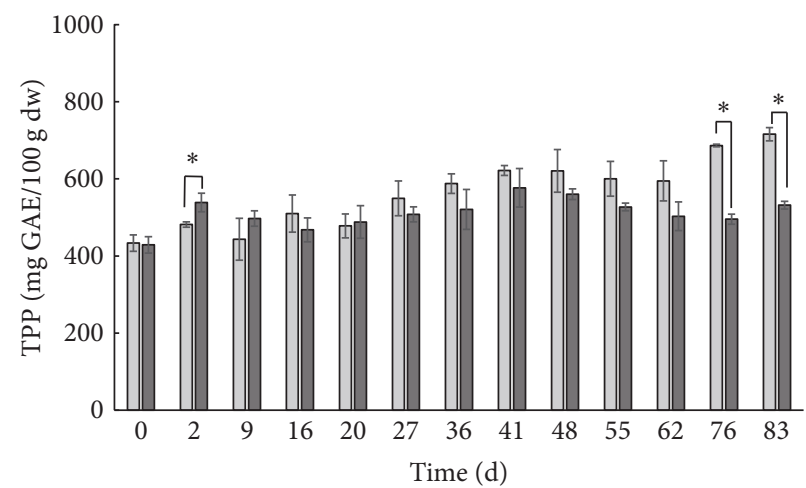

(e)

FIGURE 3: Evolution of the total polyphenols' content (TPP) in blanched (dark bars) and unprocessed (light bars) broccoli florets during storage at $20^{\circ} \mathrm{C}(\mathrm{a}), 10^{\circ} \mathrm{C}(\mathrm{b}),-1^{\circ} \mathrm{C}(\mathrm{c}),-21^{\circ} \mathrm{C}(\mathrm{d})$, and $-45^{\circ} \mathrm{C}(\mathrm{e})$. Significant differences $(p<0.05)$ between blanched and unprocessed broccoli are highlighted with “*”.

were only partially inactivated during blanching. In unprocessed broccoli, the TPP content was significantly higher than the initial content except at 20 and 48 days of storage, probably due to the higher enzymatic activity. A similar behavior was observed at $-21^{\circ} \mathrm{C}$, with TPP content being significantly higher in unprocessed broccoli than in blanched broccoli during the most part of the storage period. The TPP content in unprocessed broccoli increased during storage, being significantly higher than the initial value ( 0 days of storage). Blanched broccoli showed no significant variation of TPP content with respect to the initial condition. The variations of TPP content in blanched and unprocessed florets stored at $-45^{\circ} \mathrm{C}$ were much less marked than in the other storage conditions. At $-45^{\circ} \mathrm{C}$ the TPP content of unprocessed broccoli increased during storage, being in most cases significantly higher that the initial TPP content. This agrees with the results of Volden et al. [9], who studied the effect of long-term freezer storage (at $-24^{\circ} \mathrm{C}$ ) of different cauliflower varieties on the TPP content. The authors reported a slight increase of TPP in all the cultivars after 3 months of storage. Additionally, Ninfali and Bacchiocca [20] reported that TPP content of broccoli suffered no change after commercial freezing storage. This contradicts our results obtained at -1 and $-21^{\circ} \mathrm{C}$, but agrees with our observations after 62 days of storage at $-45^{\circ} \mathrm{C}$. 


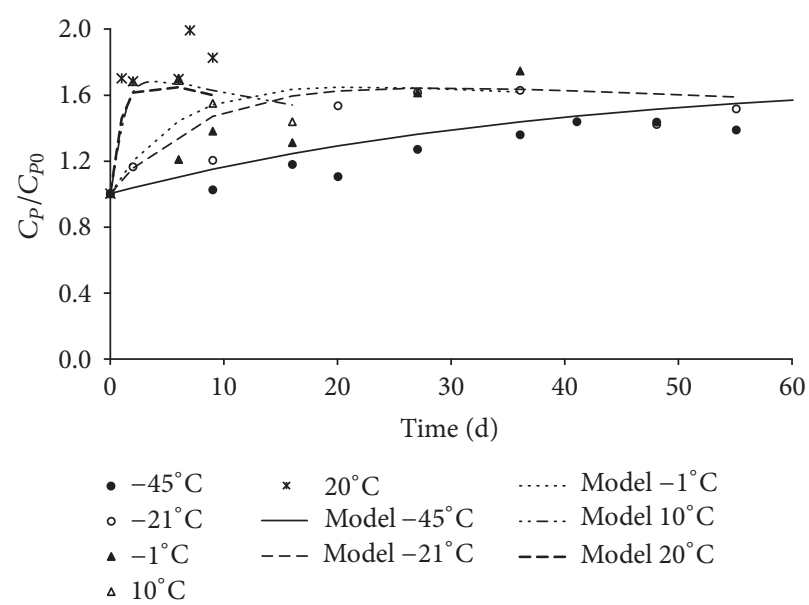

(a)

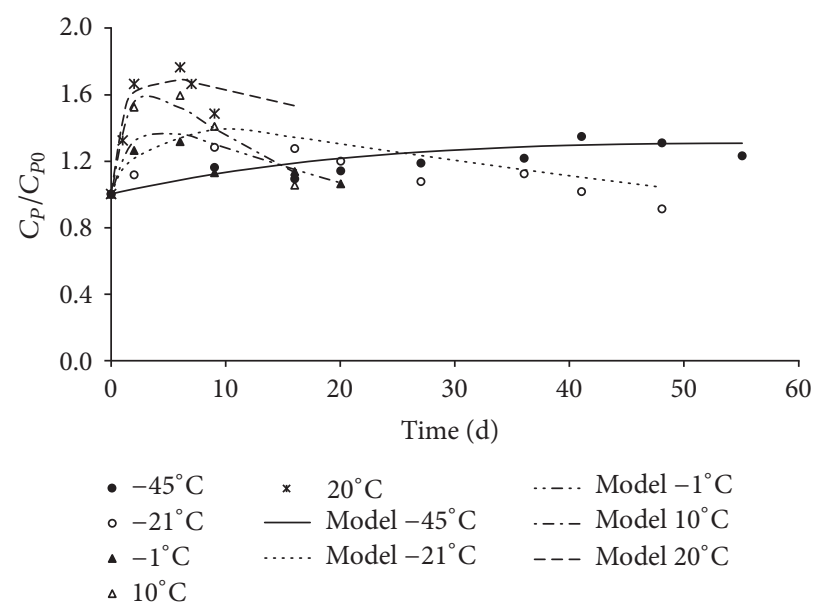

(b)

FIGURE 4: Adjustment of the two-consecutive-reaction kinetic model to TPP content in (a) unprocessed and (b) blanched broccoli during storage at different temperatures.

Kinetic Model. The evolution of TPP content in unprocessed and blanched broccoli during storage at different temperatures was described by a two-consecutive-reaction mechanism, as suggested in the literature [11]. Figure 4 shows the model adjustment for unprocessed (Figure 4(a)) and blanched (Figure 4(b)) broccoli florets. The kinetic model adjusted acceptably the experimental data, showing $r \geq$ 0.86 (Table 1). The MSE values also indicate a good fit, with values lower than 0.10 for blanched broccoli. For unprocessed broccoli the fit was somewhat more modest, with MSE ranging between 0.0412 and 0.1040 .

The polyphenols formation and degradation were faster at higher temperatures, as shown by the rate constants given in Table 1. For unprocessed broccoli, the rate constants for polyphenols formation $\left(k_{1}\right)$ fluctuated between 0.025 and $1.0 \mathrm{~d}^{-1}$, and the degradation rate constants $\left(k_{2}\right)$ varied between $1 \cdot 10^{-4}$ and $1 \cdot 10^{-2} \mathrm{~d}^{-1}$. For blanched broccoli the rate constants behaved in a similar way. These results agree with Amodio et al. [11] who adjusted the evolution of phenolic compounds in mandarin slices stored at $4^{\circ} \mathrm{C}$ to the twoconsecutive-reaction kinetics. The authors obtained $k_{1}$ and $k_{2}$ equal to 0.24 and $0.04 \mathrm{~d}^{-1}$.

Table 2 shows the activation energies obtained for unprocessed and blanched broccoli florets. For polyphenols formation in unprocessed broccoli Ea was $32 \mathrm{~kJ} / \mathrm{mol}$, and for degradation it was $38 \mathrm{~kJ} / \mathrm{mol}$. This result suggests that polyphenols degradation occurred faster than their formation, probably due to a higher activity of the endogenous or microbial polyphenol oxidase, and in addition to depletion of the precursor compounds. In blanched broccoli, Ea for polyphenols formation was $27 \mathrm{~kJ} / \mathrm{mol}$ and for degradation it was $26 \mathrm{~kJ} / \mathrm{mol}$, both being lower than in unprocessed florets. This fact may be related to the partial inactivation of both PAL and PPO by blanching.

The Ea values obtained in this work agree with the values reported by Cisse et al. [21], who studied the degradation kinetics of anthocyanin in Roselle extracts during storage.
They reported an Ea of $26 \mathrm{~kJ} / \mathrm{mol}$ considering first order degradation kinetics and the Arrhenius equation.

The Ea values obtained for formation and degradation of polyphenols in unprocessed and blanched broccoli were similar, confirming that in both cases the same reactions are responsible for the evolution of TPP content during storage.

\section{Conclusion}

Both antioxidant activity and TPP content showed an initial increase during storage at $20,10,-1$, and $-21^{\circ} \mathrm{C}$, followed by a decrease. Unprocessed broccoli florets reached higher FRSA and TPP values during storage in comparison with blanched broccoli. Storage at $-45^{\circ} \mathrm{C}$ produced no significant variation in FRSA and TPP content for both unprocessed and blanched florets. Hence storage at $-45^{\circ} \mathrm{C}$ is recommended to preserve antioxidant properties of broccoli. The uneven behavior of FRSA during storage, attributed to the multifactorial nature of this property, preclude modeling.

The two-consecutive-reaction model represented adequately the evolution of TPP content in unprocessed and blanched broccoli florets during storage, with $r \geq 0.86$ and $\mathrm{MSE} \leq 0.1$. The Ea values obtained for polyphenols formation and degradation confirm that in both unprocessed and blanched broccoli the same reactions are responsible for the evolution of TPP content. The results obtained here could contribute to design preservation strategies of broccoli in order to exploit its health-promoting properties.

\section{Nomenclature}

$C_{P}: \quad$ Concentration of total polyphenols

$C_{P 0}$ : Initial concentration of total polyphenols

$C_{\text {pre }}$ : Concentration of polyphenols precursors

$C_{\text {pre, } 0}$ : Initial Concentration of polyphenols precursors

$C_{O}$ : Concentration of oxidized polyphenols

DM: Dry matter 
TABLE 1: Kinetic parameters estimates ( $r$ and MSE) for evolution of TPP content in unprocessed and blanched broccoli stored at different temperatures. " $r$ " is the Pearson's correlation coefficient and MSE is the mean squared error. $C_{\text {pre }, 0}$ was estimated from the experimental data, and it was equal to $320 \mathrm{mg}$ GAE/g DM for unprocessed broccoli and $220 \mathrm{mg} \mathrm{GAE} / \mathrm{g}$ DM for blanched broccoli.

\begin{tabular}{|c|c|c|c|c|}
\hline Temperature $\left({ }^{\circ} \mathrm{C}\right)$ & $K_{1}\left(\mathrm{~d}^{-1}\right)$ & $K_{2}\left(\mathrm{~d}^{-1}\right)$ & $r$ & MSE \\
\hline \multicolumn{5}{|c|}{ Unprocessed broccoli } \\
\hline 20 & 1.00 & 0.0100 & 0.9318 & 0.0412 \\
\hline 10 & 0.98 & 0.0080 & 0.9679 & 0.0043 \\
\hline-1 & 0.16 & 0.0022 & 0.8815 & 0.0194 \\
\hline-21 & 0.12 & 0.0018 & 0.9172 & 0.0148 \\
\hline-45 & 0.025 & 0.0001 & 0.9374 & 0.1040 \\
\hline \multicolumn{5}{|c|}{ Blanched broccoli } \\
\hline 20 & 0.840 & 0.010 & 0.9464 & 0.0076 \\
\hline 10 & 0.800 & 0.030 & 0.9827 & 0.0025 \\
\hline-1 & 0.600 & 0.018 & 0.9059 & 0.0058 \\
\hline-21 & 0.300 & 0.008 & 0.9301 & 0.0096 \\
\hline-45 & 0.035 & 0.002 & 0.8581 & 0.0991 \\
\hline
\end{tabular}

TABLE 2: Activation energies and frequency factors obtained from the kinetic model through the Arrhenius equation.

\begin{tabular}{lcccc}
\hline & $\mathrm{Ea}_{1}(\mathrm{~kJ} / \mathrm{mol})$ & $K_{01}\left(\mathrm{~s}^{-1}\right)$ & $\mathrm{Ea}_{2}(\mathrm{~kJ} / \mathrm{mol})$ & 38 \\
\hline Unprocessed broccoli & 32 & 5 & $K_{02}\left(\mathrm{~s}^{-1}\right)$ \\
Blanched broccoli & 27 & 1 & 26 & 0.80 \\
\hline
\end{tabular}

Ea: Activation energy

FRSA: Free radical scavenging ability

GAE: Gallic acid equivalents

HPSA: Hydrogen peroxide scavenging activity

$k_{i}$ : Rate constant

MSE: Mean square error

$O: \quad$ Oxidized polyphenols

$P$ : $\quad$ Polyphenols

PAL: Phenylalanine ammonia-lyase

PPO: Polyphenol oxidase

$r$ : $\quad$ Pearson's correlation coefficient

$t: \quad$ Time

TPP: Total polyphenols content.

\section{Conflicts of Interest}

The authors declare that there are no conflicts of interest regarding the publication of this paper.

\section{Acknowledgments}

This work was supported by Proyecto Basal USA 1555 and Vridei 021711MO_PUBLIC, Universidad de Santiago de Chile.

\section{References}

[1] D. A. Moreno, M. Carvajal, C. López-Berenguer, and C. GarcíaViguera, "Chemical and biological characterisation of nutraceutical compounds of broccoli," Journal of Pharmaceutical and Biomedical Analysis, vol. 41, no. 5, pp. 1508-1522, 2006.

[2] S. A. Ganai, "Histone deacetylase inhibitor sulforaphane: The phytochemical with vibrant activity against prostate cancer," Biomedicine and Pharmacotherapy, vol. 81, pp. 250-257, 2016.
[3] M. A. Moser and O. K. Chun, "Vitamin C and heart health: a review based on findings from epidemiologic studies," International Journal of Molecular Sciences, vol. 17, no. 8, pp. 1328-1336, 2016.

[4] A. Mahn and A. Reyes, "An overview of health-promoting compounds of broccoli (Brassica oleracea var. italica) and the effect of processing," Food Science and Technology International, vol. 18, no. 6, pp. 503-514, 2012.

[5] M. D’Archivio, C. Filesi, R. Di Benedetto, R. Gargiulo, C. Giovannini, and R. Masella, "Polyphenols, dietary sources and bioavailability," Annali dell'Istituto Superiore di Sanita, vol. 43, no. 4, pp. 348-361, 2007.

[6] A. Scalbert, C. Manach, C. Morand, and C. Remesy, "Dietary polyphenols and the prevention of diseases," Reviews in Food Science and Nutrition, vol. 45, no. 4, pp. 287-306, 2005.

[7] J. Shi, H. Nawaz, J. Pohorly, G. Mittal, Y. Kakuda, and Y. Jiang, "Extraction of polyphenolics from plant material for functional foods - engineering and technology," Food Reviews International, vol. 21, no. 1, pp. 139-166, 2005.

[8] C. Cai, H. Miao, H. Qian, L. Yao, B. Wang, and Q. Wang, "Effects of industrial pre-freezing processing and freezing handling on glucosinolates and antioxidant attributes in broccoli florets," Food Chemistry, vol. 210, pp. 451-456, 2016.

[9] J. Volden, G. I. A. Borge, M. Hansen, T. Wicklund, and G. B. Bengtsson, "Processing (blanching, boiling, steaming) effects on the content of glucosinolates and antioxidant-related parameters in cauliflower (Brassica oleracea L. ssp. botrytis)," LWT - Food Science and Technology, vol. 42, no. 1, pp. 63-73, 2009.

[10] A. Patras, B. K. Tiwari, and N. P. Brunton, "Influence of blanching and low temperature preservation strategies on antioxidant activity and phytochemical content of carrots, green beans and broccoli," LWT - Food Science and Technology, vol. 44, no. 1, pp. 299-306, 2011.

[11] M. L. Amodio, A. Derossi, and G. Colelli, "Modeling phenolic content during storage of cut fruit and vegetables: a consecutive 
reaction mechanism," Journal of Food Engineering, vol. 140, pp. $1-8,2014$.

[12] C. Pérez, H. Barrientos, J. Román, and A. Mahn, “Optimization of a blanching step to maximize sulforaphane synthesis in broccoli florets," Food Chemistry, vol. 145, pp. 264-271, 2014.

[13] J. A. Vinson, X. Su, L. Zubik, and P. Bose, "Phenol antioxidant quantity and quality in foods: fruits," Journal of Agricultural and Food Chemistry, vol. 49, no. 11, pp. 5315-5321, 2001.

[14] M. Montes-Bayón, M. J. D. Molet, E. B. González, and A. SanzMedel, "Evaluation of different sample extraction strategies for selenium determination in selenium-enriched plants (Allium sativum and Brassica juncea) and Se speciation by HPLC-ICPMS," Talanta, vol. 68, no. 4, pp. 1287-1293, 2006.

[15] A. L. K. Faller and E. Fialho, "The antioxidant capacity and polyphenol content of organic and conventional retail vegetables after domestic cooking," Food Research International, vol. 42, no. 1, pp. 210-215, 2009.

[16] W. Brand-Williams, M. E. Cuvelier, and C. Berset, "Use of a free radical method to evaluate antioxidant activity," $L W T$-Food Science and Technology, vol. 28, no. 1, pp. 25-30, 1995.

[17] A. Mahn, M. Zamorano, H. Barrientos, and A. Reyes, "Optimization of a process to obtain selenium-enriched freeze-dried broccoli with high antioxidant properties," LWT - Food Science and Technology, vol. 47, no. 2, pp. 267-273, 2012.

[18] M. Oktay, I. Gülçin, and Ö. I. Küfrevioglu, "Determination of in vitro antioxidant activity of fennel (Foeniculum vulgare) seed extracts," LWT-Food Science and Technology, vol. 36, no. 2, pp. 263-271, 2003.

[19] A. Mahn and C. Pérez, "Optimization of an incubation step to maximize sulforaphane content in pre-processed broccoli," Journal of Food Science and Technology, vol. 53, no. 11, pp. 41104115, 2016.

[20] P. Ninfali and M. Bacchiocca, "Polyphenols and antioxidant capacity of vegetables under fresh and frozen conditions," Journal of Agricultural and Food Chemistry, vol. 51, no. 8, pp. 22222226, 2003.

[21] M. Cisse, F. Vaillant, A. Kane, O. Ndiaye, and M. Dornier, "Impact of the extraction procedure on the kinetics of anthocyanin and colour degradation of roselle extracts during storage," Journal of the Science of Food and Agriculture, vol. 92, no. 6, pp. 1214-1221, 2012. 

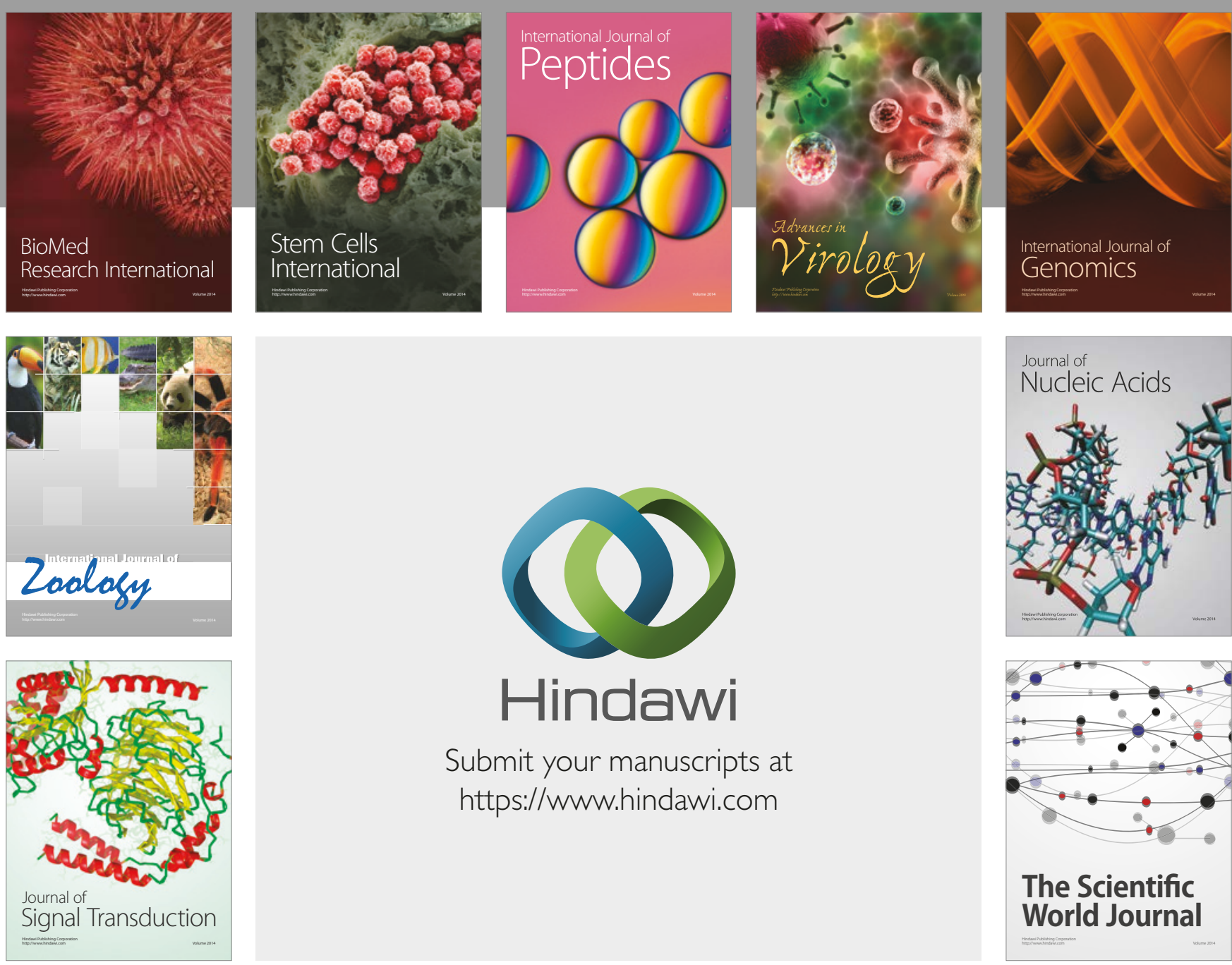

Submit your manuscripts at

https://www.hindawi.com
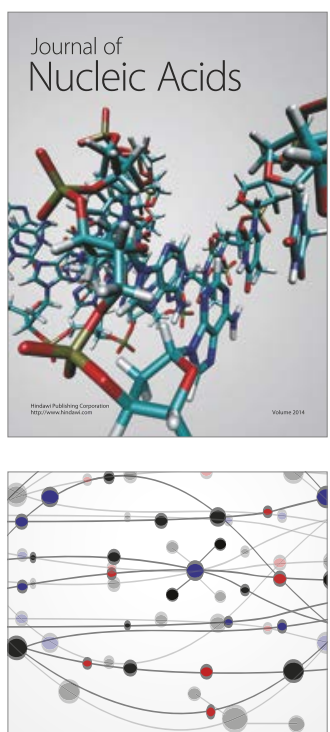

The Scientific World Journal

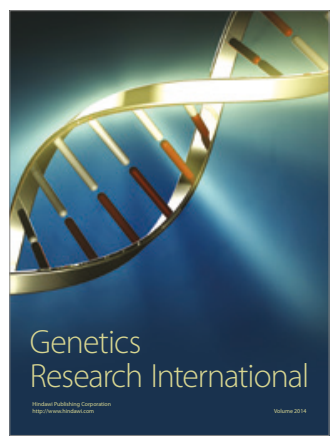

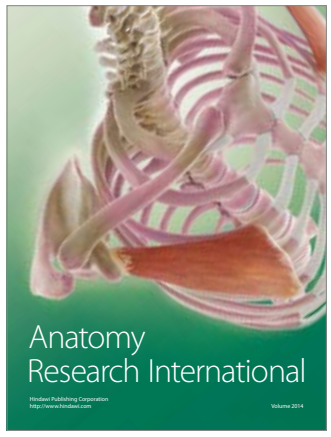

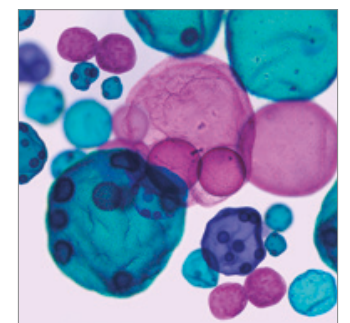

International Journal of Microbiology
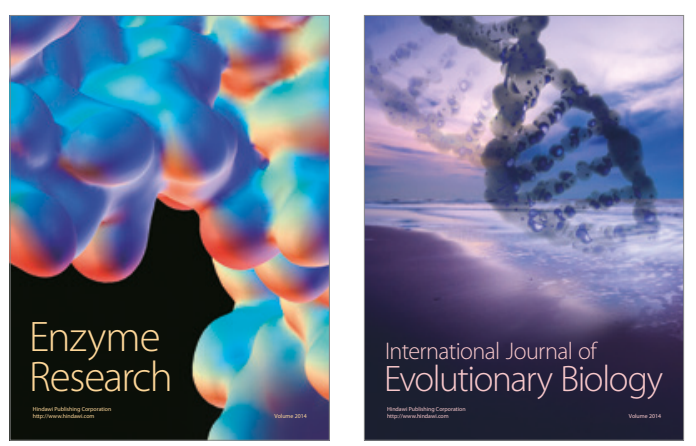
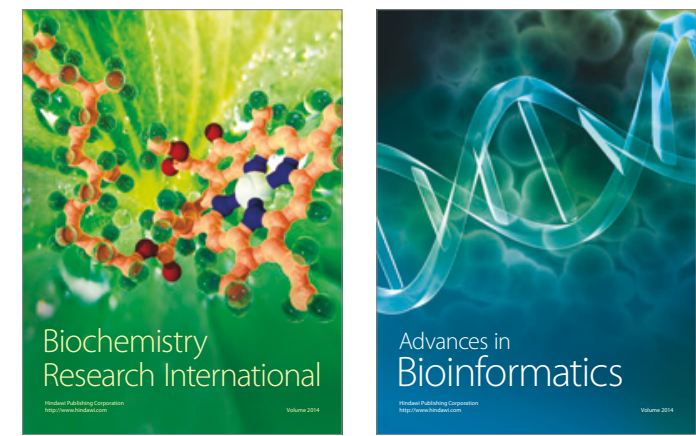

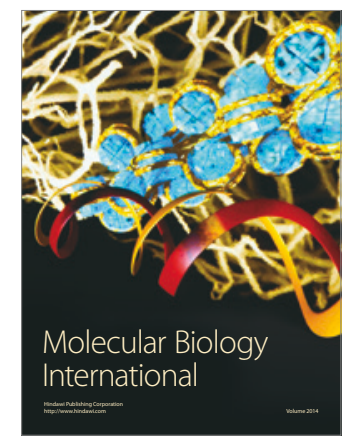

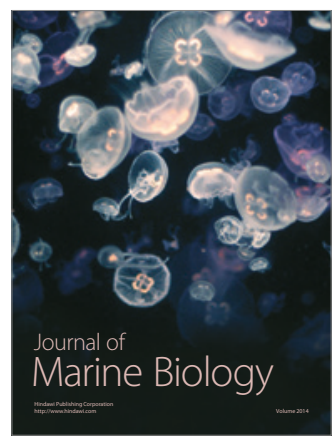

